\title{
Total knee arthroplasty 2010
}

\author{
Roland Becker
}

Published online: 5 June 2010

(C) Springer-Verlag 2010

The Bone and Joint Decade from 2000 to 2010 has almost reached his end. The decade was invited by the United Nation and the World Health Organisation in order to increase the awareness to people with musculoskeletal diseases. The rapid increase in the prevalence of osteoarthritis will have a growing impact on the health care and public health care system.

It has been estimated that the number of patients diagnosed with osteoarthritis will increase by $40 \%$ in the next 25 years. The number of patients with symptomatic osteoarthritis has grown from 21 to 27 Million in the USA between 1995 and 2005 [4]. There are several reasons for this development. First, the world population is currently increasing from 6 Billion in 2000 to almost 7 Billion in 2010 [8]. Thus, there will be more patients in the future suffering on osteoarthritis. The second major reason seems to be the aging of our world population. It has been estimated, that the number of people over an age of 60 will rise from one-fifth in 1995 to one-fourth in 2020, which means an increase of about $40 \%$ in this group of age.

Murphy et al. [6] estimated the lifetime risk of symptomatic knee osteoarthritis of about $45 \%$. Many of these patients will be potential candidates for joint replacement. Disability and pain are the major indications for total knee arthroplasty. Nowadays people getting more demanding and want to be mobile and maintain their level of activity as long as possible. According to the Swedish knee arthroplasty register the average age of the patients has

\section{R. Becker $(\bowtie)$}

Department of Orthopaedics and Traumatology,

City Hospital Brandenburg, Hochstrasse 26,

14776 Brandenburg/Havel, Germany

e-mail: roland_becker@yahoo.de dropped for total knee arthroplasty (TKA) from 72 to 69 and for unicompartmental knee arthroplasty (UKA) even down to 64 between 1995 until 2005. Based on these facts it is not surprising that the cost for total joint replacement is permanently rising and exceeds in the United States already $1 \%$ of the gross domestic product in 2007 .

The number of both primary and revision arthroplasty will increase about $300 \%$ in the next 15 years. Especially due to hip and knee arthroplasty the quality of life can be significantly improved and many of the patients return to a level of activities which makes them physically active and happy in their older days [1].

Nevertheless, not all of the patients will do perfectly well. The success rate after TKA has been reported between 80 and $90 \%$. Going into more detail the satisfaction rate in pain relief varies between 72 and $86 \%$ and for specific activities like getting in and out a car or bus $(70 \%)$ or ascending stairs (73\%) [5]. In order to find the cause for persistent knee pain after TKA may sometimes be very difficult. A new diagnostic algorithm to evaluate painful knees after TKA has been introduced by Hirschmann and co-authors [3], in the current issue. They report about a combination of both single photon emission tomography and conventional computerized tomography. This technique allows the analysis of the component position by using the reconstructed $3 \mathrm{D}$-scan. In addition it will provide information about the bone metabolic status around the knee too. However, further studies are required in order to find out whether this tool will be useful and specific enough in patients with unexplained pain following TKA on a regular basis.

Despite the improvement of diagnostic tools we have to improve our understanding of the complexity of the knee by further anatomical and kinematic studies as well. It includes the understanding for the natural knee kinematics 
but also for the kinematics of the knee after replacement. According to numerous studies using fluoroscopy we are aware of the remarkable alteration in knee kinematics after TKA. Despite our surgical skills to implant the prosthesis as perfect as possible, however it does not guarantee that the patient will always be $100 \%$ happy afterwards. Of course there might be surgical and non-surgical factors involved. In order to mimic knee kinematics after TKA as close as possible to the natural knee there are ongoing modifications in concepts and implant designs. The medial pivot TKA seems to be one example to mimic natural knee kinematics more closely. Analyses have shown internal rotation of the tibia during deep knee flexion when using these implants similar to the normal knee but in less extension [4].

The patient specific resurfacing implant based on CTscan or MRI with personalized jigs might be a concept for the future in order to preserve the bone and to respect the soft tissue around the knee even more [2]. This technique has been introduced for unicondylararthroplasty, patellofemoral arthroplasty or for combined arthroplasty of both a single tibiofemoral and patello-femoral compartment.

Despite all the improvement in TKA the increased number of primary total knee arthroplasty increases the risk for revision surgery due to several reasons, such as aseptic or septic loosening or due to persistent pain. Revision for TKA has been reported of $1.9 \%$ according to the Swedish Knee Arthroplasty register.

Coming back to the financial aspect in terms of joint replacement. The study of Oduwole and co-workers [7], which you will also find in the current issue, reports about the increasing financial burden of revision total knee arthroplasty. The analysis has been performed based on 189 patients, who received revision TKA between 1997 and 2006. They have shown that the total cost for revision surgery rises continuously mainly due to cost of diagnostic interventions and for the implants used in revision cases.
Despite the fact that the Bone and Joint Decade will end soon there is still a lot of ongoing research in order to improve our understanding about the aetiology and pathology of joint degeneration. In severe osteoarthritis joint replacement is the treatment of choice with promising long term results. However there is still enough space to improve the outcome.

\section{References}

1. Bourne RB, Chesworth BM, Davis AM, Mohamed NN, Charron KD (2010) Patient satisfaction after total knee arthroplasty: who is satisfied and who is not? Clin Orthop Relat Res 468:57-63

2. Fitz W (2009) Unicompartmental knee arthroplasty with use of novel patient-specific resurfacing implants and personalized jigs. J Bone Joint Surg Am 91(1):69-76

3. Hirschmann MT, Iranpour F, Konala P, Kerner A, Rasch H, Cobb JP, Friederich NF (2010) A novel standardized algorithm for evaluating patients with painful total knee arthroplasty using combined single photon emission tomography and conventional computerized tomography. Knee Surg Sports Traumatol Arthrosc. doi: 10.1007/s00167-010-1070-z

4. Lawrence RC, Felson DT, Helmick CG, Arnold LM, Choi H, Deyo RA, Gabriel S, Hirsch R, Hochberg MC, Hunder GG, Jordan JM, Katz JN, Kremers HM, Wolfe F (2008) Estimates of the prevalence of arthritis and theotherrheumaticconditions in the United States. Part II. Arthritis Rheum 58:26-35

5. Moonot P, Mu S, Railton GT, Field RA, Banks SA (2009) Tibiofemoral kinematic analysis of the knee flexion for a medial pivot knee. Knee Surg Sports Traumatol Arthrosc 17:927-934

6. Murphy L, Schwartz TA, Helmick CG, Renner JB, Tudor G, Koch G, Dragomir A, Kalsbeek WD, Luta G, Jordan JM (2008) Lifetime risk of symptomatic knee osteoarthritis. Arthritis Rheum 59:1207-1213

7. Oduwole KO, Molony DC, Walls RJ, Bashir SP, Mulhall KJ (2010) Increasing financial burden of revision total knee arthroplasty. Knee Surg Sports Traumatol Arthrosc. doi: 10.1007/s00167-010-1074-8

8. US Consensus Bureau, International Data Base, December 2008 Update (http://www.census.gov/ipc/www/idb/worldpopgraph.html) 